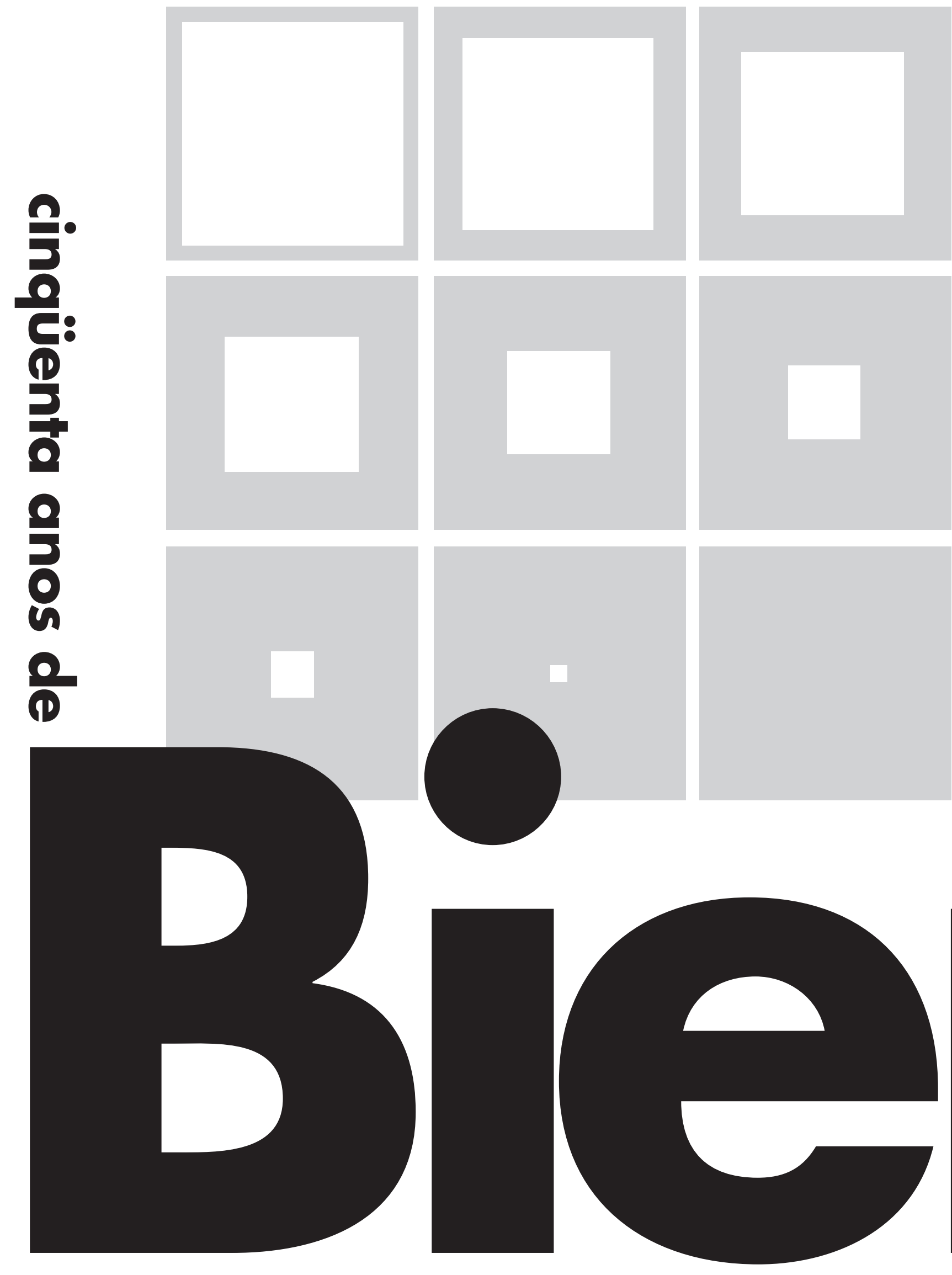


LUIZ MARQUES

é professor de História da Arte do Departamento de

História da Unicamp.

\section{A Bienal e o novo sistema das artes}

\section{LUIZ MARQUES}
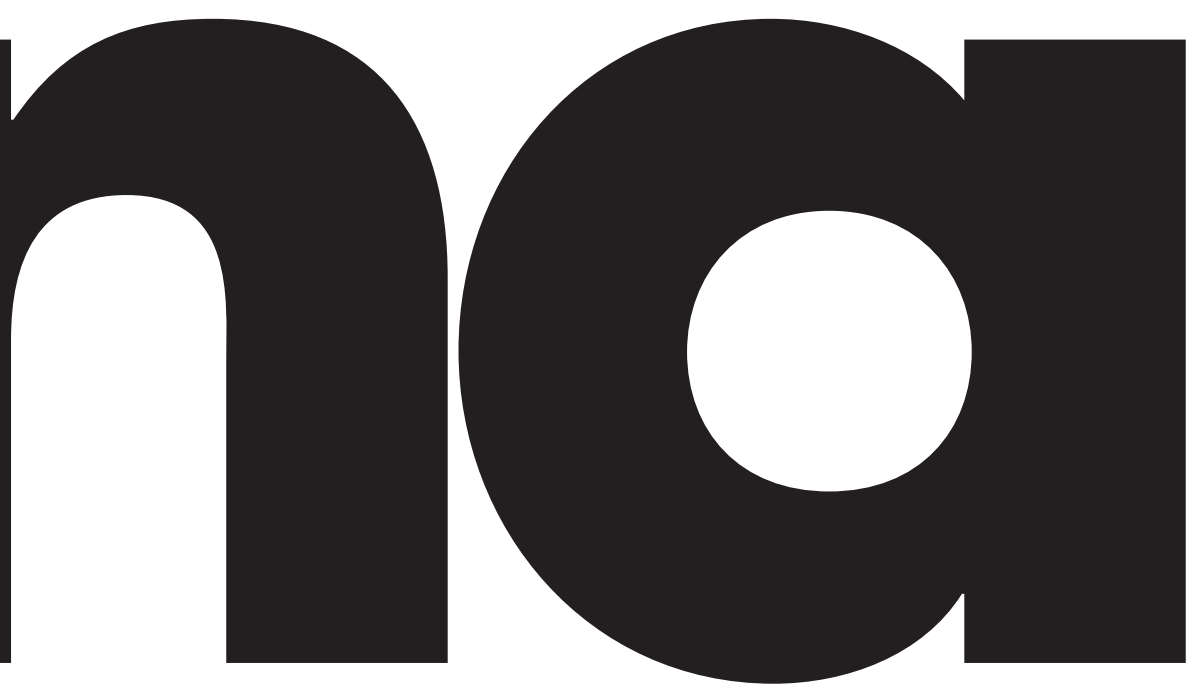
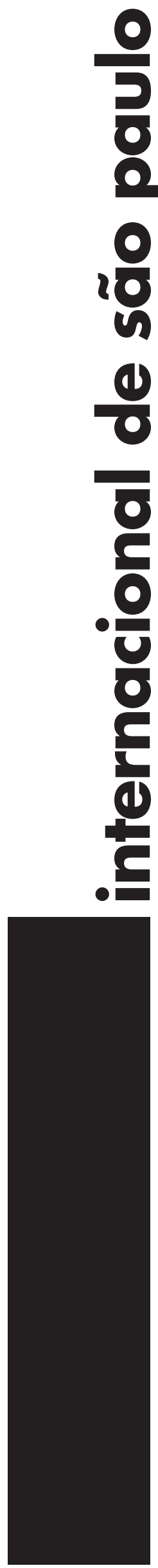


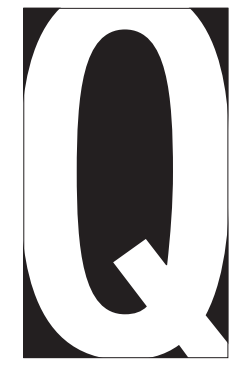

uão memoráveis terão sido as Bienais Internacionais de São Paulo até os anos 60, até notadamente a de 1967, dará bom testemunho quem quer que, interessado em artes visuais, tenha nascido antes ou ao menos não muito depois de 1950. Desde então, como se sabe, a Bienal declina. Este movimento descendente era inevitável no contexto de uma atrofia geral da inteligência e do espírito causada por vinte anos de obscurantismo nacional-militarista. Teriam porém contribuído para tanto fatores mais endógenos à cultura artística, próprios ao legado do modernismo no país e, sem dúvida, próprios também às tendências que parecem prevalecer na arte contemporânea desde a pop art. As heróicas tentativas recentes de ressuscitar o antigo apelo das Bienais de São Paulo por meio de portentosas, e de fato formidáveis, exposições de artistas clássicos da arte moderna não fazem aparentemente senão atestar a inelutabilidade de seu fado. Dessa inanidade com que se conclui a experiência histórica da Bienal de São Paulo, pode-se falar em quatro sentidos.

Ligada em seu nascimento a um projeto museológico, a um projeto de patrimônio artístico, a Bienal poderia ter sido responsável pela criação de um soberbo Museu de Arte Moderna e Contemporânea, bastando que cooptasse para seu acervo, em cada uma de suas edições, uma pequena seleção das tantíssimas, e algumas magníficas, obras expostas no Ibirapuera nos últimos cinqüenta anos. A história dos percalços desse projeto do imediato pós-guerra, dos quais redundam, desde 1969, não um, mas dois fantasmas de museus, ainda há pouco tão desprovidos, como o MAM-SP e o MAC-USP, demonstra de modo eloqüente que seu destino não poderia senão ser calamitoso. Tanto mais que as obras-primas do acervo do MAC originam-se em geral em aquisições, para o núcleo inicial do MAM e para si próprio, de Ciccillo Matarazzo e de sua esposa, Yolanda Penteado, bem informados pelo galerista alemão Nierendorf, pelo crítico belga Léon Degand, pelo pintor italiano Alberto Magnelli e pela legendária Margherita Sarfatti, pouco devendo assim à experiência sucessiva da Bienal (1).

Do fracasso da Bienal em gerar um acervo internacional expressivo - malgrado os esforços isolados de Walter Zanini-, decorre um segundo: o insucesso em dotar de coordenadas internacionais a experiência e o debate no país sobre a arte essencialmente globalizada da segunda metade do século XX. Não obstante o esforço de seus curadores (tradicionalmente brasileiros) em promover uma sempre renovada discussão das coordenadas mais amplas da arte contemporânea, a Bienal não conseguiu de fato atravessar as barreiras mentais protecionistas e impermeabilizantes de uma cultura incipiente e reflexa como a nossa; não foi em suma capaz de imprimir um impulso decisivo na superação do horizonte nacionalista do colecionismo público e privado, do mercado de arte local, e sobretudo da forma mentis dos estudiosos brasileiros da história da arte moderna, cuja agenda de pesquisas permanece ainda hoje preponderantemente referida à Semana de Arte de 22 ou aos seus fabricados mentais.

Que dos 50 anos da Bienal de São Paulo pouco ou nada enfim decorra, pode-se ainda dizê-lo em um terceiro sentido, menos vinculado este último às determinações da cultura local. Como as demais Bienais e congêneres, a de São Paulo formulou-se paulatinamente como uma contradição nos termos: ser a instituição dedicada a referendar e a atribuir o selo de "bom para comércio" aos objetos (ou "trabalhos") selecionados exatamente por terem sido julgados marginais à instituição ou (ainda) não sufragados por ela. Quanto mais envelhecem, menos tais exposições conseguem ocultar seu caráter restaurador dos salons. Mais se revelam um "salão de arte contemporânea”. Tal contradição nos termos não seria mais que uma curiosidade histórica não fosse produzir um percutante efeito de realidade: como Santo Antônio, a Bienal de São Paulo sobrevive sacralizada na 
ubiquiidade, pois ocupa a posição legitimante dos salons, exatamente porque e enquanto reivindica a não-posição, a extraterritorialidade, a negatividade crítica dos refusés.

À inanidade chega-se enfim por uma quarta via, tampouco esta exclusivamente local, a da redução ao evento. Se um historiador como Hobsbawm, para citar uma voz entre tantas do gentio, pode lamentar que a arte contemporânea "tornou-se um subdepartamento de marketing" (2),é nas Bienais que esta metamorfose entra em fase paroxística e põe a nu sua maquinaria. Mas é decerto na de São Paulo que as engrenagens do mecanismo publicitário emitem ruídos tão cacofônicos que, suprimidos os tempos mais lentos da introspecção talvez ainda requerida pela experiência artística, tudo se converte em pura performance. Uma tal operação foi facilitada, é preciso que se admita, por um aspecto inerente ao próprio programa da arte contemporânea, e não deixa de constituir um desdobramento possível de seu ideal performático.

\section{2}

Estas quatro experiências auto-anulantes garantem à Bienal, por outro lado, uma segura representatividade no quadro da cultura visual contemporânea no Brasil, retratável em quatro traços distintivos:

1) Desapreçoaos museus: uma inapetência quase total em relação à idéia de incremento do patrimônio museológico, oriunda de uma rejeição mais ampla e profunda do legado civilizacional do Museu (por mim entendido, não como instituição precursora do "centro cultural" em cujo "dinamismo" ela se redime, mas como uma enciclopédia das formas e como domínio das musas). Essa inapetência é comum a todas as camadas da sociedade brasileira, que a partilham de forma equânime;

2) Fechamento para o mundo: uma inapetência, não menor, em relação à arte internacional. Essa aparente incapacidade de prescindir de referências nacionais para pensar a cultura visual passada e presente é um típico subproduto do ideário nacionalmodernista dos anos 20, consagrado pela universidade e, por conseguinte, pela mídia cultural do país. No contexto dessa cultura nacionalista, e sob a pressão de seus interesses corporativos e comerciais, a Bienal Internacional de São Paulo tornouse funcional na medida em que serviu de mecanismo básico de projeção e consagração de artistas brasileiros no quadro dos valores (intelectuais e financeiros) da crítica e do mercado locais;

3) Fechamento para o passado: uma carência aguda de reflexão, de estudos, de propostas culturais que não tenham por referência cronológica, ideológica e conceitual a arte moderna ou contemporânea (prati-

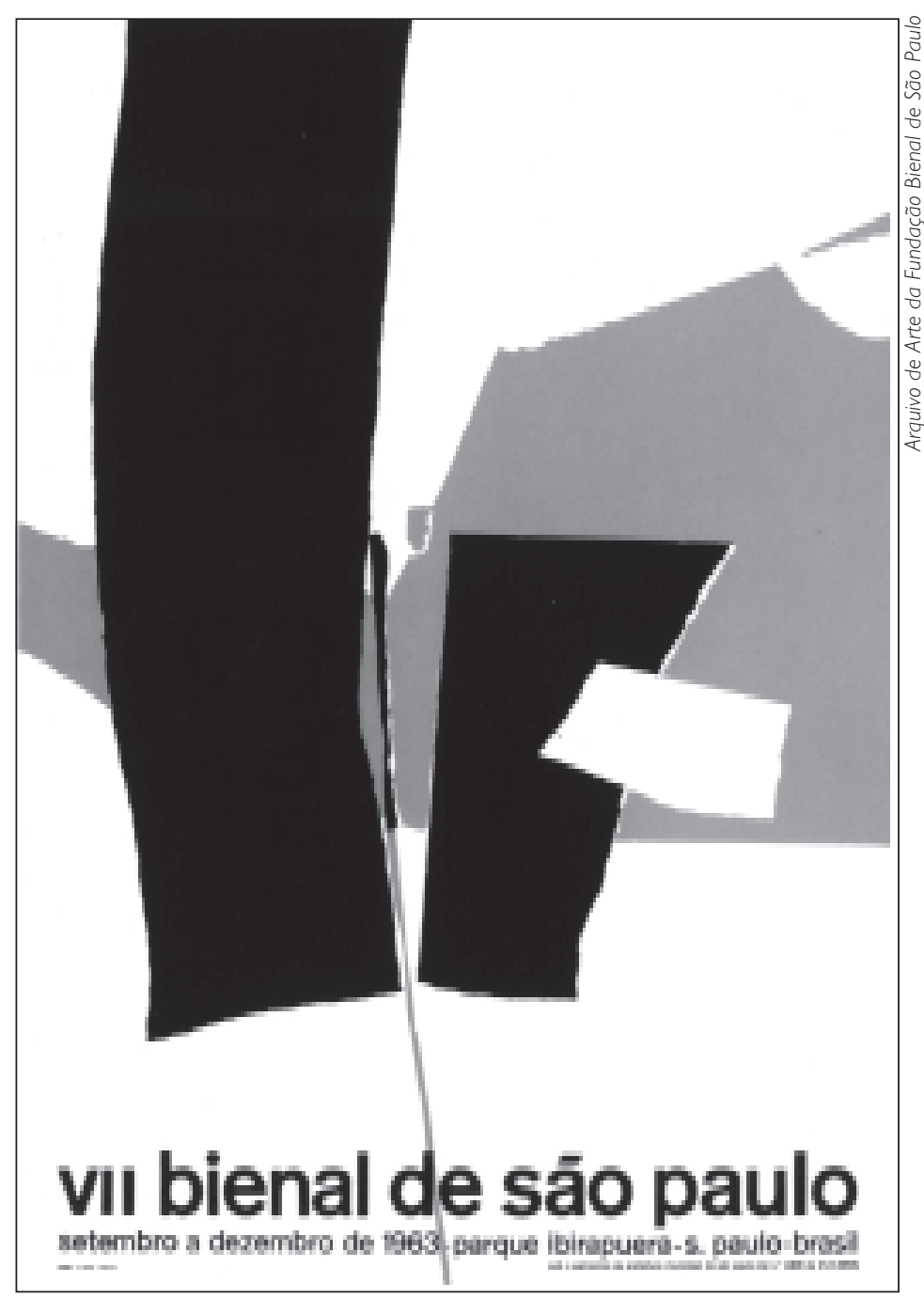


cada no Brasil), percebida como um universo de categorias autônomas e autoreferidas, que mantém com o passado apenas uma relação de conflito e superação. Essa percepção vai de par com uma indiferença particularmente acentuada pela história da arte e em especial pela tradição clássica e acadêmica oitocentista, identificada como exógenae desvirtuante de uma outrora recalcada identidade nacional. A Bienal de São Paulo passa a ser em tais condições representativa de um desejo urgente e intransigente de presente, próprio de uma cultura considerada "jovem" e vocacionalmente voltada para o futuro;

4) Invenção de uma constante histórica própria: “desalienada” dessa tradição clássico-acadêmica tida por alienígena e convencional, a cultura contemporânea local pôde rapidamente eleger ("resgatar", diriam seus ideólogos) sua matriz genuína, que remontaria ao "barroco". Pouco importa que a cultura visual do barroco não tenha de fato constituído uma matriz à qual se pudesse remeter um qualquer programa modernista no país. O equívoco se produz antes mesmo do nível da análise histórica, pois nasce de uma recusa da história. O barroco inventado pelo modernismo não é um período histórico-artístico preciso ou um estilo gravitante em torno de modelos iberohabsburguianos, mas um estado de espírito endógeno, mulato e vagamente "anti-racional”. Nacionalização do barroco e barroquização da cultura "nacional", tal é a dupla operação ideológica do nacional-modernismo pelo qual ainda se pauta a cultura contemporânea no país. Eficiente, essa dupla operação resolve de uma só vez dois problemas: a) ao "nacionalizar" o barroco, a cultura contemporânea no Brasil outorga-se um estatuto autóctone e pode resolver o problema da origem "sem sair de casa", isto é, no âmbito de seu próprio panteão nacional; b) ao tratar o barroco como um estado de espírito que fornece seu código genético, a cultura contemporânea no Brasil neutraliza a tensão passado/presente, resolvendo-a nos termos de uma espécie de psicologia profunda que tudo presentifica. Tal é a razão por que curadorias temáticas recentes da Bienal de São Paulo puderam, com universal consenso, identificar na noção nacional-modernista de "antropofagia" um "ponto de vista" brasileiro da arte contemporânea, ponto de vista que incorporaria seu próprio passado colonial. Evidentemente a idéia do barroco como arte da ilusão e do espetáculo referendaria o privilégio da performance e do acontecimento, congenial à arte contemporânea, de modo que a experiência de puro evento em que se transforma a Bienal de São Paulo não faria senão exprimir, mais uma vez, sua radicalidade como "instituição-vanguarda" representativa da cultura contemporânea no país.

\section{3}

Para além, contudo, desse jogo de recíprocas reiterações entre a cultura visual contemporânea no Brasil e a sua emblemática instituição, permanece, digno de reflexão, o problema do establishment artístico vigente em escala internacional, do qual a Bienal de São Paulo é certamente parte integrante. Permanece, em outras palavras, o problema do novo sistema internacional das artes surgido do pós-guerra, vinculado a um outro problema, o do estatuto da obra de arte contemporânea, que se imbrica com ainda outro, eminentemente filosófico, o da suspensão dojuízo. Tais problemas, aparentemente ausentes das cogitações passadas e presentes da Bienal de São Paulo, espreitam-na, entretanto, onipresentes, como surdas latências.

O problema que a todos subsume pode ser formulado da seguinte maneira: a ausência de critério para a emissão de um juízo crítico não impede que juízos se produzam, imprescindíveis que são à operacionalidade de um novo sistema internacional das artes que se sustenta sobre cinco pilares: o crítico de arte, o galerista, o agente financeiro investidor (eventualmente colecionador), o Estado e a rede internacional de salões de arte contemporânea, dentre os quais a Bienal de São Paulo. 
O efeito básico desse ajuizamento-semcritério é a redefinição do estatuto ontológico da obra de arte, redefinição que não deixou de suscitar, em perspectivas muito diferentes, desde Lévi-Strauss, Danto, Belting, Argan, Vattimo, Barzun e tantos outros, a questão do fim da arte ou, em todo o caso, do fim da assim chamada era histórica da arte (3).

Aparentemente, esse novo sistema internacional das artes, mutatis mutandis, não diferiria essencialmente do antigo, posto em funcionamento pela geração de Vasari, em meados do século XVI, e ainda operacional, malgrado tudo, em fins do século XIX. Poder-se-ia, sobretudo, contraarrazoar que o juízo crítico, base do antigo sistema internacional das artes, sempre foi problemático jamais um dado. A diferença entre ambos os sistemas não resta, por causa disso, menos abissal, e isso por duas razões. A primeira, de natureza ética ou subjetiva, é que o novo sistema, autodefinido como negação do antigo por seu caráter nãoprescritivo, não se entende e não pode se entender plenamente como sistema, sob pena de contradição nos termos, o que o faz evoluir em meio a uma perene crise de identidade e sob uma constante suspeita de má-consciência. A segunda diferença, de caráter propriamente ontológico ou objetivo, é o fato de que no antigo sistema o juízo crítico, problemático por natureza, operava a partir de um postulado de existência da obra de arte, sobre cujo atributo de excelência pairava o desafio, o risco, o problema de legislar. Reproduzia-se no ato crítico de Vasari, Lanzi, Diderot, Baudelaire ou Longhi esta tensão de matriz humanista entre a quidditas e a qualitas, isto é, entre o dado socioinstitucional (a obra de arte) e a intuição estética individual, em busca do consenso de seus pares, destinatários de uma eloqüência engenhosamente codificada (ojuízo crítico). Ora, no novo sistema internacional das artes desfaz-se essa tensão sob a pressão de três peculiaridades: a) a desmaterialização da obra; b) a instituição da originalidade como uma petição de princípio (no sentido aristotélico do termo) que, de efeito e acidente, erige-se em causa e substância da obra; e c) a definição pelo crítico do sentido e dos modos da relação da obra com o seu passado. Um exemplo pode ser aqui esclarecedor. Contestando as críticas formuladas por Jean Philippe Domecq sobre a obsessão dos artistas contemporâneos pelo ready-made, Catherine Millet afirma a respeito dos recorrentes ready-made de Bertrand Lavier: "O interesse de um trabalho como esse é precisamente o fato de pôr em crise a noção de ready-made [...]. Se proponho este exemplo muito preciso, é para dizer que não estamos em uma tradição que teria modelos" (4)

Concedamos à Millet duas atenuantes fundamentais. Há de se admitir, em primeiro lugar, que a obra de arte incorporou em sua arquitetura mais íntima, e de há muito, vale dizer desde ao menos o século XVI, a dimensão da metalinguagem, e que a crítica deve aí se instalar, hoje mais que nunca, como em seu elemento. Há ainda de se convir, em segundo lugar, que se vive há já quase um século na consciência de um mundo em que tudo é reversibilidade e indeterminação, e que a arte - e o discurso crítico por ela supostamente suscitado acusará mais que nunca a precariedade desta condição. Isso posto, a démarche de Millet parece condensar didaticamente os quatro traços mais característicos do juízo crítico em arte contemporânea:

1) Ela garante em primeiro lugar a originalidade, raiz fundamental do "interesse desse trabalho": este preciso ready-made é original (mas não haveria já aí, nessa idéia de um "ready-made original", uma contradictio in adjecto, uma contradição entre o substantivo e seu adjetivo?); ele não é um ready-made como os outros, mas um ready-made que põe em xeque a noção de ready-made, postura que resguarda sua originalidade;

2) Ela fornece, mais que isso, seu sentido, que é o de não ser essencialmente um readymade justamente porque parece sê-lo, o que confere ao juízo crítico o poder de desconstruir e reconstruir a obra a partir da pretensa revelação de sua essência;
3. Que a questão do fim da arte não prescinda de um retorno a Hegel parece indubitável. Ela toi adequadamente discutida por Paolo Gambazzi Gabriele Scaramuzza /G.W F. Hegel. Arte eMorte dell'Arte. Percorso nelle 'Lezioni di Estetica', Milão, Mondadori 1997), com ampla biblio grafia. No que se refere à crítca da críitica, não menos inprescindivel parece todavia a contribuição de Valéry em diversos ensaios, dentre os quais se destacam "La Crise d l'Esprit" (1919), bem como seu testamento" Degas, Danse, Dessin (1936), cujas teses estão já anunciadas no ano anterior no famoso "Préambule du Catalogue de l'Exposition d'Art Italien" (1935): "L'esprit de la plupart des artistes modernes est divisé contre lumême. Ils se font des systèmes qui ne se soutiennent un peu de temps que par lassistance de quelque littérature appropriée. Mais Titien, ni Véronèse, ni Robusti le Tintore n'avaient besoin qu'on les présentât. II leur suffisait de s'imposer. On leur dédiait des sonnets; on ne les expliquait pas. Ils n'offraient point des intentions, mais des miracles. Cependant, nous errons de théories en théories".

"L'intérêt d'un travail comme celuilà, c'est qu'il me précisément en crise la notion de ready-made [...]. Si i'avance cet exemple très précis, c'est pour dire que nous ne sommes pas dans une tradition qui aurait de modèles". Ver: "Tradition, Evolution, Rupture: l'A Contemporain Existe-t-i|?" mesa-redonda coordenada po Alain Cueff com intervenções de Jean Clair, Jean Philippe Domecq, Philippe Dagen Catherine Millet, Jean Philippe Antoine. Jochen Gerz, Thierry de Duve, in L'Art Contemporain: Ordres ef Désordres, colóquio promovido pelo Ministério da Cultura da França em Paris, em 26/4/1997, no âmbito dos 10 lours del'Art Contemporain. http://culture.fr/culture actual/art/debat.htm 
3) Ela ignora, ou parece ignorar, a idéia, bastante simples, que uma obra não põe em crise uma tradição por força de uma decisão (do artista ou do crítico), mas por encarnar essa tradição, os modelos dessa tradição, do modo o mais radical e o mais emblemático; 4) Mas sobretudo ela vem ancorar no mais puro nonsense ao evacuar do conceito de tradição a idéia de modelo, como se fosse possível uma tradição do nada, como se o verbo transmitir (tradere) pudesse tornarse intransitivo...

Assim, o novo sistema das artes é levado a emitir juízos cuja jurisdição estende-se não mais apenas sobre o modo de excelência da obra, mas sobre sua existência mesma. A obra, no novo sistemainternacional das artes, torna-se, em suma, de condição de possibi-

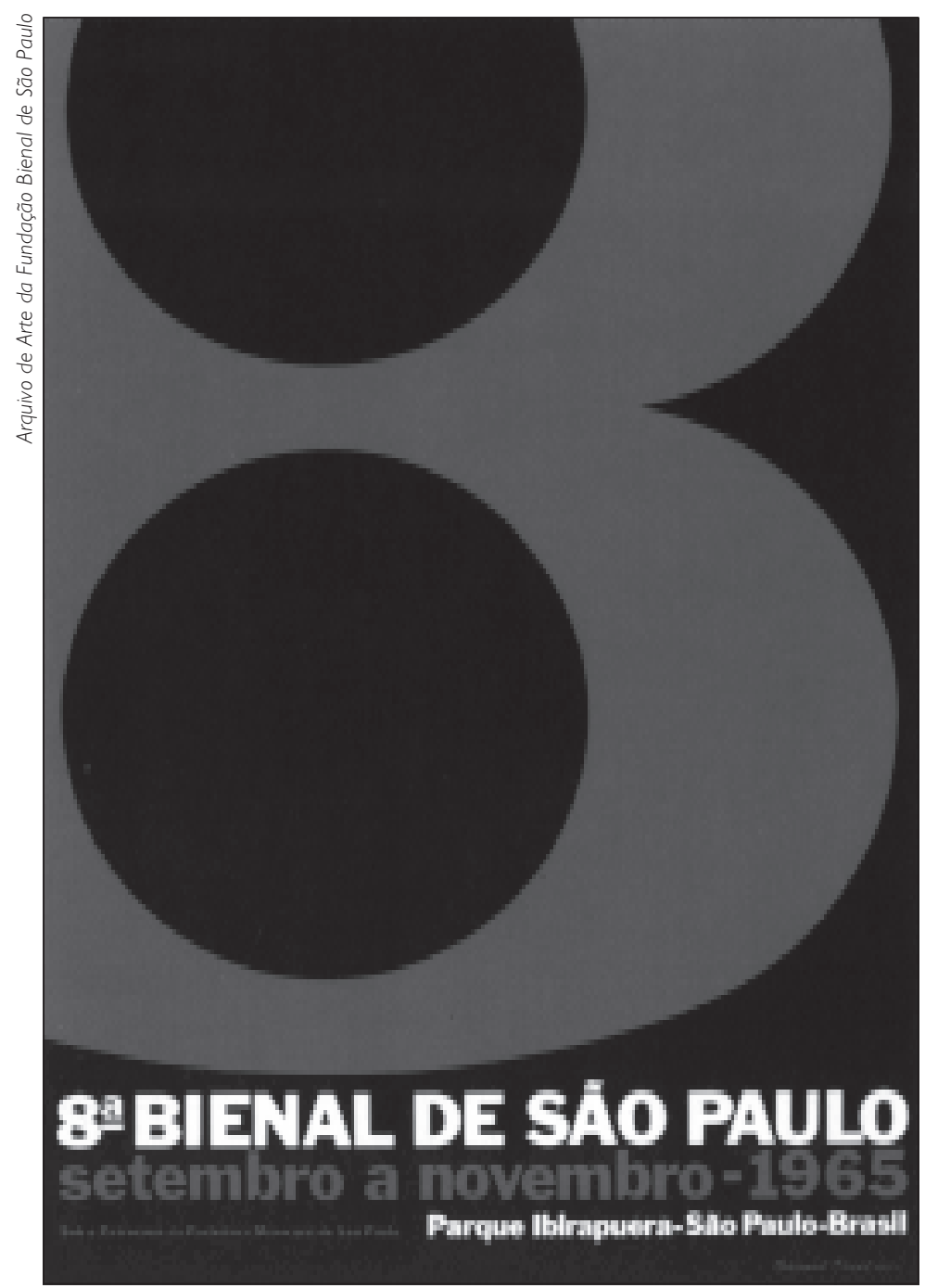

lidade do juízo, em seu corolário lógico. Em contrapartida, o juízo crítico, justamente orgulhoso de ter destruído as abordagens prescritivas do antigo sistema das artes, abandonar-se-á agora ao prazer de seus próprios enunciados performativos. O solipsismo asfixiante de um juízo crítico radicalmente imanente e pós-metafísico, que reivindica seu não-fundamento, acaba assim por se doar ele próprio como fundamento de uma obra de arte que não pode não se tornar, ipso facto, de uma nauseante redundância.

Deve-se entender esse fenômeno de inversão do sentido da informação estética, e não sem ironia, como o resultado final de um longo processo histórico de defesa da obra de arte moderna - desde Courbet e Delacroix - assumida por um grupo de clarividentes artistas e críticos de arte contra as acusações de "absurdo" e de "tolice" proferidas pelo senso comum diante de obras-primas da modernidade. Assim como Barthes referiu-se a Voltaire como o "último intelectual feliz", pois ainda podia perfeitamente distinguir as luzes do obscurantismo, assim também é possível referir-se a Alfred Barr, Roger Fry, Jean Cassou, Jean Paulhan ou mesmo Georges Duthuit, como os últimos críticos de arte felizes, pois sabiam ainda perfeitamente quem estava do lado da invenção, da audácia e da abertura de espírito e quem estava do lado da bêtise. Desde Bouvard e Pecuchet, entretanto, Flaubert descobria na bêtise uma natureza inquietantemente ambígua, descoberta que Musil retomava por conta própria em 1931 e depois em 1937 em sua conferência "Sobre a Tolice" ("Über die Dummheit"): "Se a tolice não parecesse, a se confundir, com o progresso, com o talento, com a esperança ou com o aperfeiçoamento, ninguém quereria ser tolo". Essa natureza camaleônica do sentido, que não cessa desde então de se radicalizar, gera na cultura contemporânea duas atitudes contrárias, mas simetricamente idênticas em 
sua incapacidade de "responder" à obra de arte: o silêncio e a verborragia. Talvez se desenhem, hoje, tentativas de superação desse impasse, tentativas de reinstaurar o primado do sentido na obra de arte, o que não se conceberá sem que se lhe reconheça sua própria transcendência, sua capacidade de salvar. Dentre tais tentativas, impressiona sem dúvida a de George Steiner, sobretudo em uma obra como Real Presences. Is There Anything in What We Say? (1989), à qual se recorrerá com proveito para uma densa discussão sobre as implicações desse hipercriticismo. Para Steiner, efetivamente, "o ímpeto de vontade do qual nascem a arte e o pensamento desinteressado tem suas raízes em uma aposta sobre a transcendência”. Em uma perspectiva convergente, poder-se-ia situar ainda Jean Clair, nomeadamente em seu $L a$ Responsabilité de l'Artiste (1997). Mas é em alguns dos ensaios dos anos 60 de Francis Ponge, recolhidos em L'Atelier Contemporain, que se pode sentir de novo respirar o objeto em toda a sua indiferença, livre dessa ansiedade de ser, dessa "fissura" da obra de arte contemporânea, adicta da palavra do crítico para se instalar no sentido. É em alguns desses ensaios que se pode ainda sentir a força da frase de Braque segundo a qual “l'objet, c'est la poétique”. Como quando, intérprete das naturezasmortas de Chardin, Ponge escreve: "Pourtant, chez quelques-uns seulement parmi les plus grands artistes, un pas de plus est fait. L'indifférence est atteinte" (5).
"Entretanto, em alguns somente dentre os maiores artistas, un passo a mais é dado. / A indiferença é atingida" |"De la Nature Morte et de Chardin" 1963). 